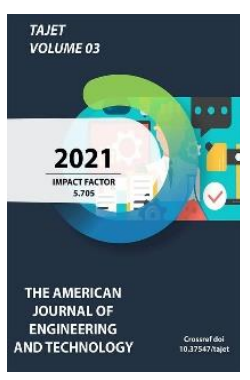

\title{
Functional And Economic Features Of The Organization Of The System Of Public Buildings In Rural Architecture
}

Dildora Fayziddinovna Ubaydullaeva

Senior Lecturer, Tashkent Institute Of Architecture And Construction, Uzbekistan

Copyright: Original

content from this work

may be used under the

terms of the creative

commons attributes

4.0 licence.

\section{ABSTRACT}

The article defines the types of public buildings that provide the rural population with a full range of cultural and social services. Also, when designing these buildings, 5 design methods were chosen and their functional and economic efficiency was taken into account. Design using these techniques can save community resources as well as provide equal services to rural and urban populations.

\section{KEYWORDS}

Villages, public buildings, settlements, design methods.

\section{INTRODUCTION}

One of the most pressing issues in the country today is the provision of all types of social services to meet the growing needs of the rural population. These services include shops, kitchens, consumer services, clubs, preschools, schools, sports complexes, communications departments, health facilities, and more. Considering that almost 50\% of the population lives in rural areas, you can see how significant this issue is. 
The "Strategy of Actions on 5 Priority Areas of Development of the Republic of Uzbekistan for 2017-2021" and the "Prosperous Village" program adopted by President Shavkat Mirziyoyev include comprehensive measures aimed at improving the well-being of the rural population. This provides an opportunity to modernize the social infrastructure of road transport to build comfortable housing.

Based on the foregoing, we can say that state programs for the development of the socioeconomic sphere of the republic will be aimed at creating a system of social services for the rural population, equal to the urban one. In addition, one of the main requirements for the formation of a system of public services is the maximum saving of material resources of the state.

\section{THE MAIN FINDINGS AND RESULTS}

The main difference between rural public buildings and urban public buildings is their small size and small size. This is due to the low density of the rural population and its fragmented location. Such a scattered distribution of rural settlements has led to the need to design different forms of public buildings. In this case, for example, instead of a large department store designed for the city, it will be necessary to create small shops to serve the same number of people in rural areas. We can see this in the system of school buildings, cultural institutions and other public buildings. However, the larger the size of public buildings, the higher the type and quality of service.

However, the current urban planning norms and regulations allow small villages to be maintained, requiring them to be equipped with small-scale social service elements, so to implement this direction, small-scale buildings or residential buildings have been turned into "small cultural homes". objects need to be developed. The construction of public buildings used in large villages, on the contrary, requires the development of large-scale projects not only for the local population, but also for the population of neighboring rural settlements.

The peculiarity of rural public buildings is that they are provided with a variety of additional features. This is because it is not possible to build small-scale separate facilities in rural areas. Because, for example, it is not right to build a school of music or choreography for several people, a children's creative house. It is more effective to place these institutions in nearby public buildings, such as houses of culture or secondary schools.

Therefore, a distinctive feature of rural public buildings is the generalization of objects of different functions in one volume. From an economic point of view, the compact location of multiple facilities reduces one-time construction costs and reduces operating costs. Architecturally, the combination of a number of small buildings into one large volume allows to create the appearance of the village community center and ensure the versatility of the use of the main public buildings.

The rapid development of agricultural production - the constant improvement of its technological processes, as well as a change in the social structure of the rural population leads to the creation of advanced types of social services and new types of buildings. At the same time, the periodic reconstruction and 
modernization of the existing fund is one of the peculiarities of rural public organizations. In addition, the reconstruction of existing social buildings, their re-equipment in accordance with modern technologies has become a distinctive feature of modernity. In other cases, the combination of old and new is very organic, creating a unique look of a whole. The adoption of old and new combinations often corresponds to the architectural tasks of merging small buildings.

Another distinctive feature of rural public buildings is the ability to expand the service infrastructure, gradually adding additional blocks separately to the generalized buildings, depending on the needs of the population. As a result of the scattered rural population, the seasonal nature of agricultural production and the multi-level system of social services, such buildings and structures have acquired a unique character. Most of them were divided into stationary buildings and mobile structures.

At the same time, the formation of the architectural plan of rural public buildings is influenced by national customs and traditions of the population, as well as natural and climatic conditions and local traditions.

Today Uzbekistan is a country that is restoring its economy and strengthening the material and technical base in all sectors of the economy. The socio-economic changes observed in the country are manifested in the large-scale construction of residential, public and industrial facilities. This will have to attract the material resources of the state. Therefore, the issue of rational and efficient use of funds is of particular importance.

Many years of experience in design construction work shows that the use of methods such as scaling, generalization, rationalization of the system, the variability of historical solutions to achieve economic savings of funds gives effective results.

The first method is enlargement - which can be clearly seen in secondary schools. According to the table below, $19.36 \mathrm{~m} 3$ per child in schools with 40 grades is $27.02 \mathrm{~m} 3$ per child in schools with 10 grades (Table 1 ).

Table 1.

Comparative technical and economic indicators of secondary schools of different capacities

\begin{tabular}{|l|c|c|c|c|c|}
\hline \multirow{2}{*}{ Indicators } & \multicolumn{5}{|c|}{ Secondary schools, number of classes } \\
\cline { 2 - 6 } & 10 & 16 & 20 & 30 & 40 \\
\hline $\begin{array}{l}\text { Total construction } \\
\text { volume, m3 }\end{array}$ & 10594 & 14696 & 17217 & 24014 & 30357 \\
\hline $\begin{array}{l}\text { Area corresponding to 1 } \\
\text { seat, m2 }\end{array}$ & 27.02 & 23.55 & 21.96 & 20.42 & 19.36 \\
\hline
\end{tabular}


It is obvious that the construction of large-scale schools can save up to $30 \%$ of material resources. The acquired material resources can be used to improve the school's interior, material and technical base, laboratories, computer rooms, cocktail rooms. When expanded, it provides full access to special training facilities such as laboratories, workshops. It should be noted, however, that large schools are fully staffed with teachers and support staff. This is significant for improving the quality of education.

The second method is co-ordination - the use of certain rooms in conjunction with several institutions. We can see this in multi-functional facilities such as community centers, palaces of culture, sports complexes. Among such projects is the construction of a community center in the village of Liprindo in the BaikalAmur region, Tashkent Zonal Research Institute of Experimental Design arx Bykov A. We can see a typical public center for the cities of Uzbekistan.

The third method is the rational organization of these service facilities, taking into account the distance and boundaries of transport and walking. The above-mentioned school project may be effective in urban areas, but given the presence of small settlements in rural areas, it may be necessary to build larger schools in these areas, separate buses for foreign students, or build boarding schools. Therefore, to avoid such unnecessary expenses, it is necessary to find their optimal placement. Given the fact that students in grades 1-4 should go to schools close to their places of residence, it is advisable to organize group schools in rural areas of Uzbekistan. That is, one large school for grades 5-9 and several small schools for grades 1-4.

The fourth tip is to condense these historical composite solutions by reducing the perimeter of the external barrier structures, shortening the internal communications. In this way, for example, a school for 1,176 students can be planned for 1,560 students.

This means that we can achieve an effective result by generalizing and expanding several buildings, taking into account the needs of the population.

The architectural-planning structure of the construction of social centers of a modern village is sometimes more meaningful in the construction of a large volume of the dominant building. Cooperative buildings are used in 200 to 500 small settlements.

In villages of average size from 1,000 to 2,000, so-called intraspecific partnerships are recommended. The collaboration of this nature includes the merging of kindergartens and nursery, shop and dining room, village council and offices in one building.

The fifth direction that will bring economic benefits is the construction of schools consisting of these functional blocks. The calculations show that, for example, four blocks of 1-4 grades and 5-9 grades, 2 household blocks, four blocks of school rooms (activity hall, gymnastics and kitchen), two curricula were developed for the schools needed for construction in rural areas of Uzbekistan, includes output workshop blocks. In this case, not only economic but also practical success can be achieved. Architectural design is, first of all, the selection of the best of the various options of design 
methods. One of the most important aspects to consider when choosing the best option is the cost-effectiveness given these scheduling factors. These coefficients are $\mathrm{C}_{1}, \mathrm{C}_{2}, \mathrm{C}_{3}$, and C4.

$\mathrm{C} 1$ - the ratio of the working area to the total area of the building,

C2 - the ratio of construction volume to the total area of the building

C3- The ratio of the area of external barrier structures to the total area of the building.

C4-The ratio of the perimeter of the external walls to the total area of the buildinghttp://fccland.ru/uploads/posts/201607/1468403922_r4.jpeg

\section{CONCLUSION}

In short, each of the coefficients on construction standards has clear economic indicators. Correspondence of technical and economic indicators to standard coefficients shows the profitability of the project and the feasibility of its implementation in construction. Using the above design methods, it is possible to create a system of services for the rural population of Uzbekistan, equal to the city, as well as save public resources.

\section{REFERENCES}

1. Ubaydullaeva D.F. "Rational organization of the network of services to the rural population of Uzbekistan" "Architecture and construction of Uzbekistan ", magazines 2-3.2016-son, Toshkent: Gosarkhitektstroy RUz, 2016. -pp.21-22.

2. Nagaeva Zarema Sadykovna the author's abstract of the dissertation of the doctor of architecture "Urban planning organization of public services of the population of Uzbekistan" Moscow: 1988.

3. Appendix 1 to the Decree of the President of the Republic of Uzbekistan No. PD-4947 dated 07.02.2017 "Strategy of actions on five priority directions of development of the Republic of Uzbekistan for 20172021". -pp.4.3

4. http://fccland.ru/tipologiyaobschestvennyh-zdaniy/740ekonomicheskiy-aspektproektirovaniya-obschestvennyhzdaniy.html 